\title{
Food guide under fire at obesity summit
}

$\mathrm{H}$ ealth Canada may soon strike juice from the fruit and vegetables food group, Director General of the Office of Nutrition Policy and Promotion Hasan Hutchinson implied at the Canadian Obesity Summit in Toronto.

It can't have been a comfortable event for Hutchinson. Throughout the summit, presenters and participants alike lambasted the scientific integrity and usefulness of Canada's Food Guide.

Some of the most pointed criticism targeted the juice issue: if the guide is free from industry influence and based on evidence, one participant needled in an Apr. 30 session, why does it still count sugary beverages as fruit?

The guide recommends that Canadians consume up to 10 servings of fruit and vegetables a day, depending on age and gender. A half-cup of juice counts as a single serving. Under this rubric, it's easy to see how a person might not think twice about having a few cups a day. The problem: even a single glass of orange juice can put you over the daily sugar limit recommended by the World Health Organization.

Initially, Hutchinson dismissed the criticism. He argued that Canadians who "actually understand" how to apply the guide's recommendations for sugar would necessarily restrict their servings of fruit and vegetables from juice.

"How many times does it say to choose low sugar?" Hutchinson levelled. "You've got a six-page document with at least eight directional statements ... so don't tell me we're not making the types of statements to choose the right types of food."

But pressed on the point during a May 1 plenary, Hutchinson acknowledged that this calculus may be beyond some Canadians. "We know [applying the portions] is sometimes problematic and we're working on that."

He also implied that Health Canada would shift emphasis away from juice as a source of fruit and vegetables: "You won't be seeing that anymore ... and there'll be a fair number of new materi-

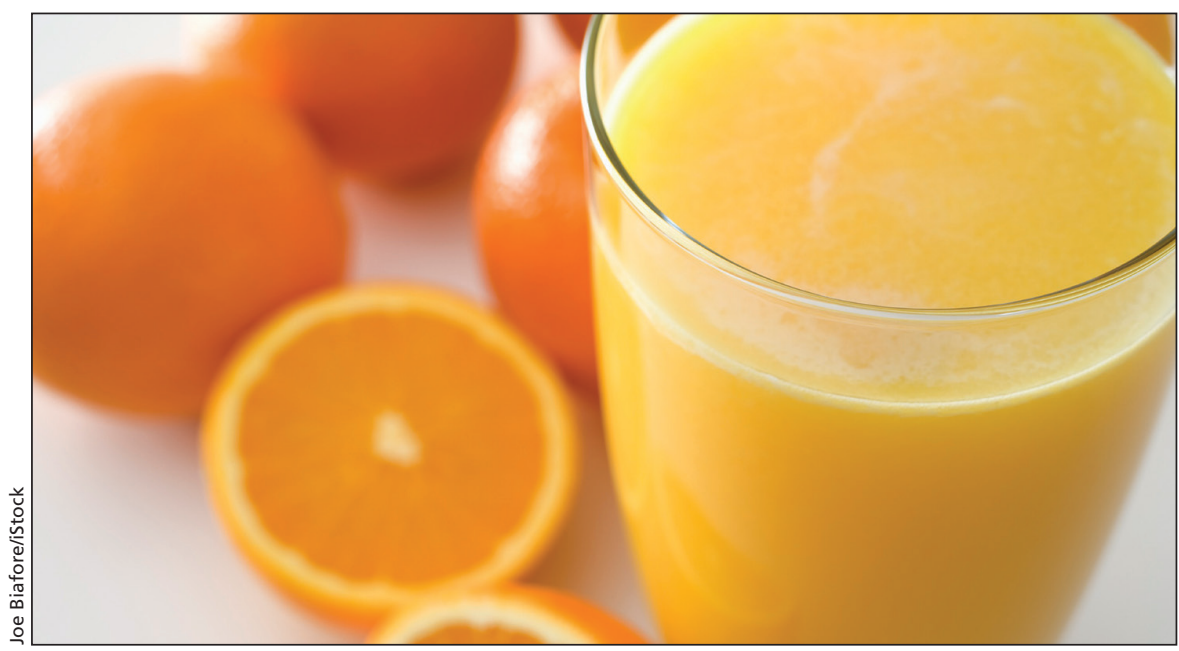

One of these things is not like the others. Presenters at the Canadian Obesity Summit criticized Canada's Food Guide for endorsing juice as a fruit serving.

als coming out in the next few months."

The ambiguity and complexity of the guide was a theme echoed across multiple presentations at the summit. In a May 1 talk, tobacco control and product regulation expert David Hammond described the guide as a "very complicated, difficult tool."

It still provides very technical measurements for portions and servings "in the way we used to provide people with numbers on cigarette packages," he noted. "We hope they'll make the right inferences from that, but they don't."

For example, "most consumers make far bigger distinctions between Coke and Minute Maid than they should [given similar calorie content], and don't make the distinction between fruit and juice that maybe they could."

Cigarette warnings have become less technical and more direct, and so should nutrition guidance, said Hammond. He cited a New York City campaign that explicitly likened fruit drinks to pop. "They've put out a specific message that I think has a greater potential to actually help people change."

Other presentations on May 2 illustrated just how little Canadians know and understand current nutrition guidance.

Lana Vanderlee, a doctoral student at the University of Waterloo, shared survey results that showed only $53 \%$ of teens and young adults can name all four food groups. Just $29 \%$ could identify the calories needed to maintain a healthy weight. And almost no one could correctly guess the recommended limits for sugar $(5 \%)$ or sodium (1\%). Despite this poor showing, $22 \%$ claimed they were very or extremely knowledgeable about nutrition.

According to Christen Rachul, a research fellow at the University of Alberta Health Law Institute in Edmonton, even registered dietitians have difficulty translating the guide for patients. "Assumptions have been made about readers' abilities to recognize and interpret things like charts, cooking measurements, and specialized terminology."

For example, "terms like folic acid, unsaturated fat and minerals require a fairly sophisticated knowledge of nutrition science," explained Rachul. Even words like "contribute" or "vitality" will be foreign to some people.

In interviews, dietitians complained that they spend most of their time teaching people to use the guide, added Rachul. "In other words, the guide doesn't help discussions about healthy eating, it becomes the discussion." Lauren Vogel, CMAJ

CMAJ 2015. DOI:10.1503/cmaj.109-5064 